\title{
Formação em MOODLE de professores de uma escola básica portuguesa: que efeitos na sua prática docente? ${ }^{1}$
}

José Rui Santos, Universidade Aberta de Portugal, jrs.univ.ab@gmail.com Maria Ivone Gaspar, Universidade Aberta de Portugal e Centro de Estudos de Desenvolvimento Humano da Universidade Católica Portuguesa, ivonegaspar@yahoo.com.br

Resumo. As tecnologias de informação e comunicação, qual alquimia da modernidade, estão presentes de forma indelével e transversal a toda atividade humana, estranho seria pois que não estivessem na escola. A legislação portuguesa impõe aos educadores de infância e professores dos ensinos básico e secundário formação contínua cíclica como condição para progressão na carreira. Tal imposição, aliada à necessidade de formação em TIC, em particular sobre a plataforma Moodle, disponibilizada na quase totalidade das escolas portuguesas, e sentida pelos professores, faz com que proliferem as ações de formação sobre essa plataforma. Neste artigo, retratam-se os efeitos práticos de uma dessas ações, a partir da análise de dados recolhidos através de inquérito por questionário, onde as principais conclusões são a pouco significante relevância que os professores atribuem ao uso da Moodle enquanto plataforma de gestão de aprendizagem e que, com ou sem formação específica, a maioria apenas a usa para aceder à informação emanada das lideranças de topo e intermédias das escolas.

Palavras-chave: formação contínua de professores, Moodle, TIC, professores.

\section{Moodle training for teacher in a Portuguese comprehensive school: what effects to their teaching practice?}

Abstract. The information and communication technologies, as the modern alchemy, are present in all human activity, so it would be very strange if they were not also present in education. The Portuguese legislation sets as compulsory some cyclical and regular training as a condition to career progression to all the teachers, not only nursery teachers but also secondary teachers. This obligation connected with the need felt by the teachers for training in ICTs, in particular in Moodle learning platform, available in almost all Portuguese schools, leads to the widespread of training in this subject. In this article, we portray the practical effects of one of those training through the analysis of data gathered by survey questionnaire. The main conclusions to be drawn are the little significance that teachers attribute to the use of Moodle as a learning platform and that, with or without specific training, most of the teachers only use it to access information sent by the high-level or middle-level leaderships of the schools.

Key-words: continuous teacher training, Moodle, ICTs, teachers.

\section{Introdução}

As tecnologias de informação e comunicação (TIC) transformaram de uma forma admirável as maneiras de comunicar, de trabalhar e de decidir, mas, também, de ensinar e aprender. E, estando presentes de forma indelével e transversal a toda atividade humana, estranho seria que não fossem encontradas na escola.

O acesso em tempo real à informação, a panóplia de formas e ferramentas de comunicação, o apelo audiovisual intrínseco à Internet e, sobretudo, a possibilidade dos

\footnotetext{
${ }^{1}$ Texto escrito em português de Portugal, de acordo com o Acordo Ortográfico da Língua Portuguesa, em vigor desde 2009.
} 
utilizadores colaborarem na organização de conteúdos, incrementada a partir de 2004 pela web $2.0^{1}$, que as TIC trouxeram, acabaram por, lentamente, derrubar alguns dos muros e contornar quase todos os obstáculos que a escola portuguesa colocou, no final do século passado, à sua plena penetração e integração. Os professores foram deixando pelo caminho alguns dos receios e reticências que no início deste novo milénio ainda colocavam à presença das TIC na escola e, hoje, a questão sobre a sua utilização em contexto escolar foi substituída pela interrogação sobre a forma como são utilizadas, em particular na sala de aula, para o ensino e a aprendizagem (Santos \& Gaspar, 2014).

Uma das ferramentas tecnológicas a que a escola portuguesa aderiu com maior facilidade, determinação e entusiasmo foi a Learning Management System (LMS), criada no final dos anos noventa do século passado, por Martin Dougiamas: a plataforma ${ }^{2}$ Moodle $^{3}$. Não será difícil perceber e aceitar os motivos dessa adesão, porquanto esta plataforma de gestão de aprendizagem tem características que a tutela da educação em Portugal $^{4}$ e a sua escola pública apreciam, tornando-a fortemente apetecível.

Na realidade, a Moodle é um software de código livre, gratuito e universal (Martins \& Giraffa, 2008; Santos, 2012). Permite disponibilizar conteúdos de forma aberta ou apenas para grupos fechados de utilizadores, assim como abrir espaços de discussão (fóruns e chats), reflexão de apoio à aprendizagem que podem ser utilizados pelos alunos, tendo sempre em conta a presença (ainda que assíncrona) do professor. E, possibilita, também, "o desenvolvimento de metodologias e materiais de apoio inovadores que incluam, de forma crítica, estudantes e professores no mundo actual” (Bastos et al., 2012, p. 11).

Não menos importante, e do ponto de vista da sua mera utilização pelos professores, será o facto de a comunicação com os alunos poder ser feita de forma assíncrona (fóruns) ou síncrona (nos fóruns e chats). Lembre-se a propósito que a plataforma Moodle surge como um software projetado para atuar como sala de aula virtual, com o intuito de produzir e gerenciar atividades educacionais, baseadas no uso da Internet e/ou de redes locais.

Para o desvanecimento dos receios e reticências, em particular o medo em serem substituídos pela “máquina” (Costa, 2004), que, tal como já referido, os professores, no início deste novo milénio, ainda, tinham relativamente à presença das TIC na escola, muito terá contribuído o incremento dado pelo governo português através do Plano Tecnológico da Educação (PTE) ${ }^{5}$. Contudo, parece-nos ter sido o Sistema de Formação e de Certificação em Competências TIC $^{6}$ para docentes em exercício de funções nos estabelecimentos da educação pré-escolar e dos ensinos básico e secundário, que, em 2009, se constituiu como o definitivo franqueador das portas da escola portuguesa àquilo que julgamos ser o promotor da mais recente revolução mundial, e que nos atrevemos a apelidar como a alquimia da modernidade: as TIC.

À data, efetivamente não eram só os receios dos professores que se constituíam como obstáculos à implantação/utilização das TIC na escola. Também a sua falta de formação na área e domínio das TIC, quer na formação inicial (Peralta \& Costa, 2007), quer na formação contínua (Amante, 2007; Costa, 2004, 2007; Paiva, 2002; Peralta \& Costa, 2007; Ponte, 2002, Santos; 2012, 2013), se estabelecia como fator determinante para a não utilização das TIC em contexto escolar pelos professores. Repare-se no que afirmam Pedro et al. (2008) relativamente ao caso específico da utilização da plataforma Moodle:

a falta de formação dos professores para utilizar a plataforma Moodle aparece como o factor que acolhe maior consenso por parte das escolas, quer em termos limitativos, quer em termos de necessidades sentidas pelos 
docentes, no que concerne a uma efectiva utilização das plataformas de aprendizagem nas escolas (p. 40).

A procura de formação contínua nas área das TIC sofreria um novo e revigorante impulso a partir de fevereiro de 2012, já que aos desígnios da tutela da educação decretados pelo Sistema de Formação e de Certificação em Competências TIC, juntouse, nessa altura, a obrigatoriedade da formação contínua cíclica de professores como condição para a sua progressão na carreira ${ }^{{ }^{2}}$. Esta conjugação de fatores legislativos, aliada à, e justo será referir, vontade de uma parte dos docentes portugueses em realizar, voluntariamente, formação na área das TIC, levou à proliferação de ações de formação nessa área. Igualmente justo será também referir que já em finais de 1992, princípios de 1993, o governo tomou medidas para garantir formação contínua gratuita aos docentes, em particular, através dos Centros de Formação de Associação de Escolas (CFAE) ${ }^{8}$. Não se pense porém que a importância da formação de docentes era nessa altura um facto novo ou recente, porquanto ela havia já passado "a estar no centro das políticas educativas desde os meados do século XX, com a expansão da escolarização de massas e, em particular, com a «explosão escolar» ocorrida nos anos 60” (Canário, 2007, p. 133).

No final do ano letivo de 2013/14, no âmbito da formação contínua de professores, realizámos uma ação de formação, na modalidade de curso de formação ${ }^{9}$, no mesmo agrupamento de escolas, adiante designado apenas por escola, onde, em 2009, realizámos uma investigação sobre a utilização da sua plataforma Moodle (Santos, 2012, 2013). Este curso, com a duração de vinte e cinco horas presenciais, abordava a temática de gestão e dinamização da plataforma Moodle e pretendia capacitar os professores para o seu uso, quer em contextos puramente comunicacionais, quer em contextos de ensino e aprendizagem. Como resultado final, era esperado que cada formando/professor criasse uma página/disciplina na plataforma Moodle dessa escola, para usar, dentro e fora da sala de aula, com os alunos de uma turma ou/e unidade curricular, em atividades de comunicação, informação e de ensino e aprendizagem.

Volvidos dois meses após o início do ano letivo seguinte (2014/15), voltámos a essa escola para investigar, através de um inquérito por questionário, os efeitos práticos produzidos na relação que os professores participantes nessa ação de formação mantêm com a plataforma Moodle e o tipo de uso que lhe dão, em especial no que toca à página criada durante o curso de formação. Paralelamente, interessou-nos, ainda, perceber se efetivamente os professores procuram a formação nas TIC para mudarem a forma como com elas se relacionam para o ensino, ou se apenas procuram esse tipo de formação para cumprir a, atrás referida, obrigatoriedade de formação contínua, como condição para a progressão na carreira docente imposta pela tutela da educação em Portugal.

\section{Objetivos do estudo}

Ainda antes de falarmos dos objetivos do estudo, cremos ser importante conhecer os objetivos do curso de formação, até para melhor compreensão das questões colocadas no inquérito realizado aos professores. Eram três esses objetivos: (i) proporcionar aos formandos ${ }^{10}$ conhecimento e experiência que lhes permitisse poder criar e configurar páginas dedicadas ao ensino na plataforma Moodle; (ii) executar as funcionalidades disponíveis no ambiente da plataforma Moodle e utilizar as suas ferramentas de forma a permitir um maior envolvimento, criatividade, motivação e aprendizagem de alunos; (iii) dotar os formandos de competências para a utilização das ferramentas de criação de conteúdos e atividades na plataforma Moodle. 
Deixamos já expresso na introdução deste artigo que os objetivos deste estudo passavam, essencialmente, pela pesquisa dos efeitos práticos, no curto prazo, decorrentes da frequência do curso. A este nível, era, sobretudo, nosso propósito perceber se alguma coisa e, em caso afirmativo, o quê, mudou na atitude dos formandos perante a plataforma Moodle e na utilização que lhe dão, entre o pré e o pós formação. Pretendíamos, também, conhecer quer as motivações iniciais dos formandos para a realização da ação de formação e as expectativas por eles criadas, quer o aporte $a$ posteriori, por eles percebido, dado ao seu desenvolvimento profissional. Para o efeito, no final do curso, foi expressamente solicitado a cada um dos formandos que revelasse quais tinham sido as motivações que o levaram à inscrição na ação de formação e que fizesse uma análise/previsão do impacto da formação no seu desenvolvimento profissional. Era também nossa intenção perceber se a disciplina criada ao longo do curso teve continuidade/utilidade prática, ou seja, quantos professores passaram a utilizar a plataforma Moodle para o ensino com atividades de aprendizagem.

\section{Metodologia e caracterização do objeto de estudo}

Atendendo a que iriamos fazer uma pesquisa empírica para investigar um fenómeno atual dentro do seu contexto real, ou seja um estudo de caso (Yin, 2009), e que este tipo de design permite abordagens metodológicas de natureza quer qualitativa quer quantitativa, optámos por realizar um inquérito por questionário, no qual houve o cuidado de conseguir algum equilíbrio entre as perguntas abertas e fechadas (Hill \& Hill, 2008), de modo a garantir um compromisso entre a objetividade dos comportamentos a estudar e o grau de detalhe e de liberdade na sua abordagem (Ghiglione \& Matalon, 1993).

O curso de formação foi frequentado por 19 professores, sendo apenas três do género masculino, oriundos de diferentes grupos de docência, mas todos a lecionar na mesma escola e, consequentemente, com acesso à mesma versão e configuração da plataforma Moodle.

\section{Motivações para a ação, análise e previsão do impacto da formação}

Tal como fizemos referência no ponto 2 deste artigo, no final do curso solicitámos aos professores que frequentaram a ação de formação que nos falassem das suas motivações para essa realização. Pedimos-lhes, também, que fizessem uma análise/previsão do impacto da formação no seu desenvolvimento profissional. Mostramos, a seguir, algumas das suas mais significativas revelações.

\subsection{Motivações para a realização da ação de formação}

Várias são as motivações apontadas pelos formandos para justificar a sua inscrição na ação de formação. Desde logo o facto de a LMS da escola ser a Moodle: “Ao chegar à escola onde leciono atualmente deparei-me com a plataforma Moodle e com o seu uso diário para várias finalidades. Assim aguçou-se também a necessidade de atualizar e melhorar os conhecimentos relacionados com este software" (F1); "A inscrição para a frequência desta ação foi motivada pelo interesse em saber trabalhar e saber criar uma disciplina na plataforma Moodle, uma vez que na escola se utiliza esta plataforma” (F6); "Descobrir mais potencialidades educativas da plataforma Moodle, que a nossa escola já utiliza de forma sistemática desde o ano letivo de 2007/2008” (F9).

A necessidade de fazer formação para cumprimento da legislação em vigor é comum a vários formandos, quer de forma implícita quer de forma explícita: "Em primeiro lugar, apraz-me dizer que me inscrevi nesta ação pela necessidade de formação 
contínua” (F4); "necessitava de fazer as horas de formação consideradas na legislação" (F9); "Não sendo meu propósito escamotear o facto de a própria legislação nos impor, enquanto profissionais na área do ensino, formação nesta área...” (F10); "necessidade de frequentar uma ação acreditada" (F12); "Necessidade profissional de créditos de formação para a progressão na carreira” (F16).

Muito apontada foi a necessidade de aprendizagem sobre a plataforma Moodle: "A minha principal motivação foi aprender o básico para utilizar a plataforma Moodle” (F5); "Decidi frequentar a ação de formação (...) para adquirir e desenvolver os meios necessários para atingir o conhecimento desejado” (F13).

Igualmente muito apontada é a necessidade, face à importância das TIC, de atualização: "Os motivos que me levaram a frequentar a ação de formação (...) prendem-se com a necessidade de atualização na área das tecnologias da informação e comunicação” (F10); “a participação nesta ação de formação decorre da importância da atualização dos conhecimentos nas novas tecnologias que estão em constante evolução e de desenvolver competências que me permitam uma correta aplicação das mesmas" (F18); “Os avanços das tecnologias da informação e da comunicação exigem, da parte dos professores, um investimento permanente na sua formação nestas áreas, de forma a acompanharem os novos métodos de difusão do saber e a construírem uma infoalfabetização" (F19).

A inovação em contexto sala de aula: “As tecnologias de informação e comunicação, e de modo particular a plataforma moodle, constituem um recurso particularmente rico e fomentador da inovação no contexto de sala de aula” (F8) e o interesse na criação de um ambiente de aprendizagem interativo: " $\mathrm{E}$, do exposto, facilmente deduzimos o interesse que a plataforma Moodle pode ter para nós professores para adquirirmos e desenvolvermos os meios necessários para podermos propiciar aos nossos alunos um ambiente de aprendizagem interativo, a partir de uma dinâmica e extensa partilha de informação, ideias e opiniões, que constituem meios preciosos no processo de ensino e aprendizagem. E, daí que a motivação para a frequência desta ação tenha sido enorme.” (F15); "para adquirir as ferramentas necessárias para poder propiciar aos meus alunos um ambiente de aprendizagem interativo, a partir de uma dinâmica e extensa partilha de informação, ideias e opiniões, que constituem meios preciosos no processo de ensino e aprendizagem” (F13), constituíram-se, igualmente, como fatores motivacionais.

\subsection{Análise/previsão do impacto da formação no seu desenvolvimento profissional}

As análises/previsões do impacto da formação no seu desenvolvimento profissional foram feitas pelos formandos sobre vários pontos de vista. Dividimos esses pontos de vista em quatro grupos e trazemos à liça as expressões que melhor os sintetizam: (i) melhoria das competências profissionais e criação de estratégias de ensino inovadoras: "Esta formação possibilitou-me a aquisição de capacidades, competências e atitudes ditas transversais à minha atividade docente e que me dotou com estratégias de ação que me permitem assumir-me como professora interveniente, crítica, solidária e empreendedora" (F11); (ii) "fornecendo-me um leque de estratégias inovadoras, nomeadamente na interação com os meus alunos” (F15); (iii) melhoria da comunicação com os alunos e implantação de novas dinâmicas e práticas educativas: "A disponibilização aos alunos, da disciplina criada na Plataforma Moodle do Agrupamento, vai promover, por um lado, um melhoramento da comunicação, sempre que necessário, além do contexto sala de aula, e por outro, implementação de novas dinâmicas e práticas educativas, através de maior diversificação de atividades/recursos, e instrumentos de avaliação de fácil acesso aos alunos, que lhes permitam desenvolver capacidades” (F12); (iv) aquisição de novas competências e uso de novas ferramentas e 
métodos de trabalho: "Esta ação contribuiu, também, para a promoção do desenvolvimento de novas competências, assim como, para a consolidação de competências já adquiridas” (F15); (v) "Neste momento considero que consigo trabalhar com os meus alunos na plataforma Moodle explorando novas ferramentas e métodos de trabalho" (F16); (vi) perceção sobre a utilidade da plataforma Moodle: "esta ação de formação se revelou muito proveitosa, no sentido em que os conhecimentos adquiridos poderão ser aplicados no meu trabalho diário com os alunos (...) percebi finalmente a grande utilidade da plataforma. A possibilidade de colocar online uma série de recursos a que os alunos poderão ter acesso em casa, na biblioteca da escola ou em qualquer local com internet, e hoje em dia são incontáveis esses locais, fez-me perceber que estaria a desperdiçar um instrumento de trabalho que me permitiria estar longe e ao mesmo tempo muito próxima dos meus alunos. Também me permitiria fazer algo quase impossível, como estar em casa e esclarecer dúvidas que não houve tempo para esclarecer na sala de aula a diferentes alunos e ao mesmo tempo" (F1).

\section{Análise dos resultados obtidos com o inquérito por questionário}

No, já referido, estudo por nós realizado em 2009, dos 24 inquiridos (21\%) de um universo de 113 professores, apenas oito (33\%) afirmavam ter realizado formação sobre a plataforma Moodle. À data do início do curso de formação em estudo, conforme se constata na figura 1, apenas 4 (21\%) dos 19 professores que frequentaram a ação haviam já feito formação sobre Moodle.

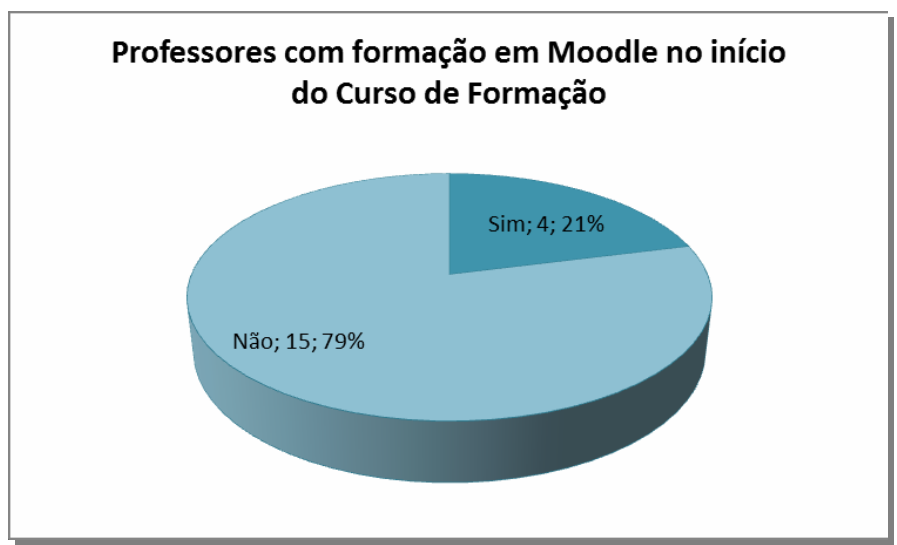

\section{Figura 1 - Professores com formação em Moodle antes do início do Curso de Formação}

Assumimos não dar grande significado a este aparente decréscimo de professores com formação em Moodle na escola que se verifica entre 2009 e 2014. Este aspeto pode ser o reflexo da instabilidade do quadro de professores da escola, fruto da mobilidade anual do corpo docente nas escolas portuguesas ou da contratação anual e cíclica de professores, sem vínculo à função pública, para suprir necessidades pontuais de falta de professores dos quadros de escola, a que se alia, ainda, o facto de o uso da plataforma Moodle pelas escolas não ter carácter de obrigatoriedade.

O mesmo não se passa relativamente à formação em TIC, aliás julgamos mesmo preocupante que o número de professores com formação nessa área esteja ainda longe dos $100 \%$, conforme se pode verificar na figura 2, sobretudo se tivermos em conta o esforço dos CFAE e das escolas em garantir formação gratuita ao seu corpo docente, bem como da tutela, através do apetrechamento das escolas em material informático (via PTE), e da já referida imposição de formação nas TIC aos professores. 


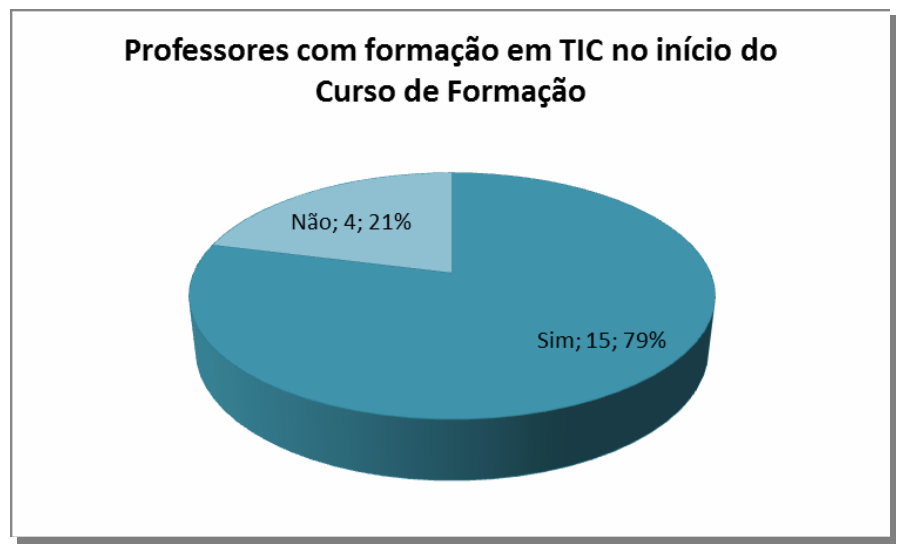

Figura 2 - Professores com formação em TIC antes do início do Curso de Formação

Conforme se pode constatar pela observação do quadro 1, dos dezanove professores que frequentaram o curso de formação, treze deles já usavam a plataforma Moodle antes do seu início. Destes, apenas dois (F3 e F7) não tinham realizado qualquer formação na área das TIC e dos onze que já a tinham realizado apenas três (F1, F10 e F11) tinham feito formação específica sobre a plataforma Moodle. Dois (F2 e F15) dos seis professores que não utilizavam a plataforma Moodle, passaram a usar depois do curso de formação.

\section{Quadro 1 - Formação Vs utilização da plataforma Moodle pelos professores}

\begin{tabular}{|c|c|c|c|c|c|c|c|c|}
\hline \multirow[t]{2}{*}{ FORMANDO } & \multicolumn{4}{|c|}{$\begin{array}{l}\text { Antes da realização do Curso } \\
\text { tinha formação em: }\end{array}$} & \multicolumn{2}{|c|}{$\begin{array}{c}\text { Antes da realização do Curso } \\
\text { de Formação utilizava a } \\
\text { plataforma Moodle? }\end{array}$} & \multicolumn{2}{|c|}{$\begin{array}{c}\text { Depois da realização do } \\
\text { Curso de Formação utiliza a } \\
\text { plataforma Moodle? }\end{array}$} \\
\hline & \multicolumn{2}{|c|}{ TIC } & \multicolumn{2}{|c|}{ Moodle } & SIM & NÄO & SIM & NÄO \\
\hline F1 & \multicolumn{2}{|c|}{ Sim } & \multicolumn{2}{|c|}{ Sim } & $x$ & & $x$ & \\
\hline F2 & \multicolumn{2}{|c|}{ Sim } & \multicolumn{2}{|c|}{ Não } & & $x$ & $x$ & \\
\hline F3 & \multicolumn{2}{|c|}{ Não } & \multicolumn{2}{|c|}{ Não } & $x$ & & $\mathrm{x}$ & \\
\hline F4 & \multicolumn{2}{|c|}{ Sim } & \multicolumn{2}{|c|}{ Não } & $\mathrm{x}$ & & $\mathrm{x}$ & \\
\hline F5 & \multicolumn{2}{|c|}{ Sim } & \multicolumn{2}{|c|}{ Não } & $\mathrm{x}$ & & $\mathrm{x}$ & \\
\hline F6 & \multicolumn{2}{|c|}{ Sim } & \multicolumn{2}{|c|}{ Não } & $x$ & & $x$ & \\
\hline F7 & \multicolumn{2}{|c|}{ Não } & \multicolumn{2}{|c|}{ Não } & $\mathrm{x}$ & & $\mathrm{x}$ & \\
\hline F8 & \multicolumn{2}{|c|}{ Sim } & \multicolumn{2}{|c|}{ Não } & & $\mathrm{x}$ & & $\mathrm{x}$ \\
\hline F9 & \multicolumn{2}{|c|}{ Não } & \multicolumn{2}{|c|}{ Não } & & $\mathrm{x}$ & & $\mathrm{x}$ \\
\hline F10 & \multicolumn{2}{|c|}{ Sim } & \multicolumn{2}{|c|}{ Sim } & $x$ & & $x$ & \\
\hline F11 & \multicolumn{2}{|c|}{ Sim } & \multicolumn{2}{|c|}{ Sim } & $x$ & & $x$ & \\
\hline F12 & \multicolumn{2}{|c|}{ Sim } & \multicolumn{2}{|c|}{ Não } & $x$ & & $x$ & \\
\hline F13 & \multicolumn{2}{|c|}{ Não } & \multicolumn{2}{|c|}{ Não } & & $x$ & & $x$ \\
\hline F14 & \multicolumn{2}{|c|}{ Sim } & & & $\mathrm{x}$ & & $\mathrm{x}$ & \\
\hline F15 & & & & & & $\mathrm{x}$ & $\mathrm{x}$ & \\
\hline F16 & & & & & $x$ & & $\mathrm{x}$ & \\
\hline F17 & & & & & $x$ & & $\mathrm{x}$ & \\
\hline F18 & & & & & & $x$ & & $\mathrm{x}$ \\
\hline F19 & & & & & $x$ & & $x$ & \\
\hline & Sim & Não & Sim & Não & & & & \\
\hline Totais & 15 & 4 & 4 & 15 & 13 & 6 & 15 & 4 \\
\hline
\end{tabular}

Para três dos professores (F8, F9 e F13) a justificação dada para a não utilização da plataforma Moodle depois de concluída a ação de formação é a "falta de disponibilidade”. Já o outro (F18) dos quatro professores que também não a utiliza afirma: "Ainda não comecei a usar por falta de tempo. Neste ano letivo estou a lecionar 3 níveis e todos têm de ser preparados de acordo com as novas metas curriculares. Por outro lado, tenho pela primeira vez um grupo de alunos de Ensino Especial, cujos materiais têm de ser todos adaptados“".

Antes da realização da ação de formação os professores utilizavam a plataforma Moodle para consulta de informação. Apenas três deles afirmaram utilizar a plataforma para outra funcionalidade para além da recolha de informação: "utilizo para retirar recursos” (F1); "trabalho com alunos; trabalho com colegas de departamento” (F11), 
mas não esclarece o tipo de trabalho realizado; e "na dinamização da: disciplina da minha área curricular; disciplina relacionada com o Projeto Educar para a Saúde” (F19), também não esclarecendo em que consiste essa dinamização. Os professores não utilizadores da plataforma Moodle antes da realização do curso alegaram "falta de conhecimentos" (F2, F8, F9, F13 e F19) e "falta de disponibilidade e de conhecimentos" (F15).

Dos quinze professores que utilizam a plataforma Moodle depois da ação de formação, seis utilizam-na em contexto pedagógico (F2, F3, F11, F12, F15 e F19). Noutro contexto afirmam utilizar doze professores: "Utilizo para retirar recursos e consultar convocatórias e informações do departamento" (F1); "Consultar as convocatórias" (F4); "Na orientação e fornecimento de informações aos Diretores de Turma“ (F5); "Para consulta de informações do Agrupamento (reuniões, documentação, legislação...)” (F6); "Para visitar as disciplinas que lá existem“ (F7); “Consulta das disciplinas em que me encontro inscrita" (F10); "Gerir um Departamento" (F11); "Consulta de disciplinas do agrupamento" (F12); "Para consulta de informação do Agrupamento" (F14); “para ter acesso a informações” (F16); “Informação de departamento, outros departamentos, correio e direção..." (F17); "Na administração da disciplina Edusa, do Educar para a Saúde, e dinamização da disciplina do Departamento de Ciências Matemáticas e Experimentais, no que se refere aos documentos da disciplina do grupo disciplinar de Ciências Físico-Químicas” (F19). Apenas três professores afirmam utilizar em contexto pedagógico e noutro contexto (F11, F12 e F19).

Apenas cinco professores utilizam a disciplina criada durante a ação de formação e fazem-no para apoio às suas disciplinas curriculares (F2, F11, F15 e F19). O docente F3 utiliza a disciplina criada como "apoio para realizar novos trabalhos". No quadro 2 podem-se observar as situações em que essa disciplina é utilizada e a utilização que lhe é dada pelos professores.

Quadro 2 - Utilização da disciplina (ou página) criada na ação de formação

\begin{tabular}{|c|c|c|c|c|c|c|}
\hline \multicolumn{7}{|c|}{ Utilização da disciplina criada na ação de formação } \\
\hline & Formando & $\mathbf{F 2}$ & $\mathbf{F 3}$ & F11 & F15 & F19 \\
\hline \multirow{4}{*}{$\begin{array}{l}\text { Situações } \\
\text { em que utiliza }\end{array}$} & Na sala de aula & $\mathrm{x}$ & $\mathrm{x}$ & $\mathrm{x}$ & $\mathrm{x}$ & $\mathrm{x}$ \\
\hline & Fora da sala de aula, no seu horário de componente não letiva na escola & & $\mathrm{x}$ & $\mathrm{x}$ & & $\mathrm{x}$ \\
\hline & Fora da sala de aula, no seu trabalho em casa & $\mathrm{x}$ & & $\mathrm{x}$ & $\mathrm{x}$ & $x$ \\
\hline & Outra(s) situação(ões) & & & & & \\
\hline \multirow{11}{*}{$\begin{array}{l}\text { Utilização } \\
\text { dada }\end{array}$} & Informação/Comunicação & $\mathrm{x}$ & & $\mathrm{x}$ & $\mathrm{x}$ & $\mathrm{x}$ \\
\hline & Fóruns de dúvidas & & $\mathrm{x}$ & & $\mathrm{x}$ & $\mathrm{x}$ \\
\hline & Disponibilização de recursos e materiais de apoio à aprendizagem & $\mathrm{x}$ & & $\mathrm{x}$ & $\mathrm{x}$ & $\mathrm{x}$ \\
\hline & Realização de trabalhos & $\mathrm{x}$ & $\mathrm{x}$ & $\mathrm{x}$ & $\mathrm{x}$ & $\mathrm{x}$ \\
\hline & Testes & $\mathrm{x}$ & & & & $\mathrm{x}$ \\
\hline & Criação de glossários & & & & $\mathrm{x}$ & $\mathrm{x}$ \\
\hline & Inquéritos/sondagens & & & & & $\mathrm{x}$ \\
\hline & Wikis & & & & $x$ & $\mathrm{x}$ \\
\hline & Chat com os alunos & & & & & $\mathrm{x}$ \\
\hline & Chat entre os alunos & & & & $\mathrm{x}$ & \\
\hline & Outra(s) & & & & & \\
\hline
\end{tabular}

Aos quatro professores que não voltaram a utilizar a plataforma Moodle, incluindose pois no grupo dos não utilizadores da disciplina (página) criada durante a ação de formação, juntam-se dez professores que indicam vários motivos para o não fazerem. A falta de tempo e de disponibilidade é o motivo indicado por cinco professores (F1, F4, F6, F7 e F16). Os restantes cinco professores indicam diferentes motivos: "Ainda não utilizei porque os assuntos lecionados nas diferentes turmas não se adaptam a realização de atividades via Moodle” (F5); "No presente ano letivo não leciono Português, 
disciplina criada na formação” (F10)”; “[falta de] atualização da minha disciplina para ser utilizada neste ano letivo" (F12); “A inscrição dos alunos na plataforma começou a ser feita há pouco tempo" (F14); "Por falta de tempo, embora reconheça a sua importância, mas tenciono fazê-lo ainda este ano" (F16). Registe-se que o professor F7, deixou no campo destinado a observações do inquérito por questionário realizado, a seguinte observação: “Ainda não utilizei, mas pretendo fazê-lo. São muitas as solicitações, porém espero brevemente encontrar disponibilidade para investir nesta muito nova ferramenta para mim.”; e o professor F12 deixou, nesse mesmo campo, a afirmação: "Pretendo utilizar, neste ano letivo, a disciplina que criei na ação de formação. Necessito, no entanto, de atualizar alguns tópicos relativamente aos anos letivos que leciono, presentemente".

\section{Conclusões}

Neste estudo, ressalta de imediato o impacto pouco significativo que a formação produziu nos professores que a realizaram, quer no que diz respeito à mudança de atitude perante a plataforma Moodle, quer no que confere ao tipo de utilização dada. Saliente-se que nem o facto da plataforma Moodle ser, como havíamos já constatado em 2009 (Santos, 2012, 2013), o meio privilegiado de informação/comunicação utilizado pelas lideranças de topo (direção) e intermédias (coordenação de departamento) da escola, levou a que após a realização da ação de formação quatro dos seis professores que não a utilizavam mudassem de atitude e os dois professores que passaram a utiliza-la apenas o fazem para consulta de informação e de convocatórias.

Deixando, desde logo, claro que não pretendemos fazer juízos sobre as motivações individuais dos professores presentes na decisão em realizarem a ação de formação, a conclusão a que chegamos é a de que uma expressiva parte deles não segue o principio defendido por Canário (2007) para quem "ser professor, hoje, implica um esforço de aprendizagem e melhoria permanentes que se inscreve numa dinâmica de formação contínua a ser mais entendida como um direito e menos como uma imposição” (p. 146).

Fazendo fé nos depoimentos recolhidos no final da ação de formação, são vários os professores que a realizaram apenas para cumprir as disposições legislativas sobre formação contínua de professores emanadas pela tutela da educação. Esta nossa convicção não só se baseia na constatação da existência de quatro professores a não utilizar a plataforma Moodle, mas, também, nos depoimentos dos professores a propósito das suas motivações para a realização da ação. No ponto 4.1 deste artigo leem-se declarações explícitas de cinco professores para quem a ação de formação foi realizada para respeitar a legislação em vigor sobre formação contínua de professores.

Começamos as nossas conclusões a falar do pouco significativo impacto que a formação produziu nos professores que a realizaram no que diz respeito à mudança de atitude perante a plataforma Moodle. E, se tal é verdade, não é menos verdade que relativamente ao tipo de utilização dada, o panorama não é melhor. De facto, também o uso dado à Moodle pouco mudou. Veja-se que, depois da formação, a plataforma continua a ser usada basicamente para consulta de informação e de convocatórias. Dos cinco professores que usam a plataforma para o ensino e atividades de aprendizagem, apenas dois não a utilizavam em qualquer circunstância.

No estudo que realizámos em 2009, o motivo mais invocado pelos professores para a não utilização da plataforma Moodle era a falta de formação. Nesse estudo, podiam-se ler revelações do tipo: "primeiro sinto que preciso de formação, preciso de aprender realmente a trabalhar com a plataforma”. Decorridos cinco anos, verificamos que apesar de adquirida a formação, tão desejada em 2009 como condição para que os professores utilizassem a plataforma Moodle para algo mais do que a simples consulta de 
informação, a maioria deles continuam a fazer o que já faziam, ou seja, ou não usam ou usam para recolha de informação burocrática.

\section{Notas de texto}

${ }^{1} \mathrm{O}$ termo web 2.0 surgiu em 2004 através da empresa americana de media O'Reilly Media, Inc. (inicialmente designada por O'Reilly \& Associates), criada por Tim O'Reilly.

${ }^{2}$ Sistema de hardware, construído com diversas ferramentas que suporta o software; no caso de plataforma para aprendizagem, com 3 grandes finalidades: comunicação, informação e interação.

${ }^{3}$ Modular Object-Oriented Dynamic Learning Environment.

${ }^{4}$ Ministério da Educação e Ciência.

5 Aprovado em setembro de 2007 pelo Governo, o PTE é o maior programa de modernização tecnológica das escolas portuguesas. "O PTE interliga de forma integrada e coerente um esforço ímpar na infraestruturação tecnológica das escolas, na disponibilização de conteúdos e serviços em linha e no reforço das competências TIC de alunos, docentes e não docentes.” Cit. in http://www.pte.gov.pt/pte/PT/OPTE/index.htm

${ }^{6}$ Criado pela Portaria n. ${ }^{0}$ 731/2009, de 7 de julho, o Sistema de Formação e de Certificação em Competências TIC, impôs à formação dos docentes para o uso das tecnologias de informação e comunicação um carácter de obrigatoriedade, assumindose, nesse diploma, a efetiva importância que estas ferramentas têm na preparação dos cidadãos no uso das novas tecnologias.

${ }^{7}$ Alínea c), do número 2, do artigo 37..$^{\circ}$ do Estatuto da carreira Docente na sua redação atual (Decreto-Lei n. ${ }^{\circ}$ 41/2012, de 21 de fevereiro).

${ }^{8}$ Constituídos em finais de 1992, início de 1993, na sequência da publicação do Decreto-lei n. ${ }^{\circ}$ 249/92, de 9 de novembro, os Centros de Formação de Associação de Escolas (CFAE), têm como objetivos (artigo 19. ${ }^{\circ}$ ) incentivar a autoformação, a prática de investigação e a inovação educacional; promover a identificação das necessidades de formação; dar resposta a necessidades de formação identificadas e manifestadas pelos estabelecimentos de educação e ensino associados e pelos respetivos educadores e professores; fomentar o intercâmbio e a divulgação de experiências pedagógicas; e adequar a oferta à procura de formação.

${ }^{9} \mathrm{O}$ curso de formação é uma das quatro modalidades possíveis de ações de formação, previsto no regime jurídico da formação contínua de professores (alínea c) do artigo $6^{\circ}$ do Decreto-Lei n. ${ }^{\circ}$ 22/2014, de 11de fevereiro.

${ }^{10}$ Por formandos entenda-se os professores que realizaram a ação de formação.

\section{Referências Bibliográficas}

AMANTE, L. Infância, escola e novas tecnologias. In: COSTA, F.A; PERALTA, H.; VISEU, S. (Orgs.). As TIC na educação em Portugal. Concepções e práticas. Porto: Porto Editora, 2007. p. 102-123.

BASTOS, G.D.; MARSHALL, D.; STORGATTO, G.A.; BORGES, L.L.; BORGES, E.L.P. O Moodle como mediador no processo de formação pedagógica: uma pesquisaação sobre a experiência de futuros professores em estágio extracurricular. RENOTE Revista Novas Tecnologias na Educação, Porto Alegre. v. 10, n. 1, 2012.

CANÁRIO, R. Formação e desenvolvimento profissional de professores. In: Ministério da Educação - Direç̧ão-Geral dos Recursos Humanos da Educação. Conferência Desenvolvimento profissional de professores para a qualidade e para a equidade 
da Aprendizagem ao Longo da Vida. Lisboa: Ministério da Educação - DirecçãoGeral dos Recursos Humanos da Educação, 2007. p. 133-148.

COSTA, F.A. O que justifica o fraco uso dos computadores na escola?. Polifonia, Lisboa. v. 7, p. 19-32, 2004.

COSTA, F.A. Tecnologias em educação - um século à procura de uma identidade. In: COSTA, F.A; PERALTA, H.; VISEU, S. (Orgs.). As TIC na educação em Portugal. Concepções e práticas. Porto: Porto Editora, 2007. p. 14-30.

GHiglione, R.; MATAlON, B. (1993). O Inquérito. Teoria e Prática. Oeiras: Celta Editora, 1993. p. 360.

HILL, M. M.; HILL, A. Investigação por Questionário (2. ${ }^{a}$ ed.). Lisboa: Edições Sílabo, 2008. p. 378.

MARTINS, C.A.; GIRAFFA, L. CAPACIT@NDO: uma proposta de formação docente. RENOTE - Revista Novas Tecnologias na Educação, Porto Alegre. v. 6, n. 2, 2008.

O’REILLY, T. What Is Web 2.0. set. 2005. Disponível em: <http://oreilly.com/web2/ archive/what-is-web20.html>. Acesso em 10 nov. 2014.

PAIVA, J. expectativas e resistências face às TIC na escola. In: COSTA, F.A.; PERALTA, H.; VISEU, S. (Orgs.). As TIC na educação em Portugal. Concepções e práticas. Porto: Porto Editora, 2007. p. 203-213.

PEDRO, N.; SOARES, F.; MATOS, J.F.; SANTOS, M. Utilização de Plataformas de Gestão de Aprendizagem em Contexto Escolar - Estudo Nacional. Centro de Competência RTE da Faculdade de Ciências da Universidade de Lisboa. Financiado pela Equipa CRIE/Direção Geral de Inovação e Desenvolvimento Curricular (não editado), (2008). Disponível em: <.http://nonio.fc.ul.pt/actividades/sem_estudo_ plat/relatorio_final_estudo_plataformas_2008.pdf>. Acesso em 10 nov. 2014.

PERALTA, H.; COSTA, F.A. Competência e confiança dos professores no uso das TIC. Síntese de um estudo internacional. Sísifo. Revista de Ciências da Educação, Lisboa. v. 3, p. 77-86, 2007.

PONTE, J.P. As TIC no início da escolaridade - Perspetivas para a formação inicial de Professores”. In: PONTE, J.P. (Org.). A Formação para a Integração das TIC na Educação Pré-Escolar e no 1. ${ }^{\circ}$ Ciclo do Ensino Básico. Porto: Porto Editora, 2002. p. 19-26.

SANTOS, J.R. A Moodle nas práticas pedagógicas de uma escola básica: realidade ou ficção na inserção das TIC em sala de aula. Educação, Formação \& Tecnologias, Braga, Portugal. v. 5, n. 1, p. 72-83, 2012.

SANTOS, J.R. A utilização da plataforma MOODLE na escola básica: realidade ou ficção na inserção das TIC em sala de aula. In: Grave, L.; Bastos, G.; Gaspar M.I. (Coord.). Lideranças e Novas Dinâmicas Educacionais. Lisboa: Universidade Aberta de Portugal, 2013. p. 124-134.

SANTOS, J.R.; GASPAR, M.I. TIC nas escolas portuguesas: contributos das lideranças.

Revista EDaPECI, São Cristovão. v. 14, n.1, p. 36-54, 2014.

YIN, R. K. Case study research. Design and methods (4. ${ }^{\mathrm{a}}$ ed.). Thousand Oaks, California: Sage Publications, 2009. p. 240. 